\title{
As consultas por correio electrónico e as mudanças organizativas na Medicina Geral e Familiar
}

Isabel Santos*

The real voyage of discovery consists not in seeking new lands but in seeing with new eyes.

Marcel Proust (1871-1922)

A s mudanças organizativas na MGF e o consequente maior envolvimento dos profissionais de enfermagem, de apoio domiciliário, assistentes sociais, psicólogos e outros profissionais na prestação de cuidados de saúde implicam que a continuidade de cuidados, em termos da relação entre um médico de família e o seu paciente, seja preenchida por outras relações, com outros membros da equipa. Esta relação médico-doente, na filosofia dos cuidados centrados na pessoa e da decisão partilhada, vê-se ainda preenchida por outros canais informativos e de ajuda, como seja o acesso a sistemas multimédia e interactivos com a informação em saúde que os doentes procuram (tratamentos, diagnóstico ou aconselhamento). Aos anteriores factos acresce a proliferação de computadores, pessoais e nos consultórios/centros de saúde, que o desenvolvimento tecnológico permitiu.

A relação médico-doente tem hoje mais interferências do que há 30 anos atrás. O modo ou a via para o seu estabelecimento e concretização pode ser por escrito, por via telefónica, por vídeo-conferência, por correio electrónico, em contactos directos ou indirectos. Estas diversas modalidades de entrar em contacto e de consultar representam enormes desafios para a prática da MGF, em particular quando se almeja manter a qualidade da interacção na prestação de cuidados personalizados, mediante uma boa comunicação interprofissional entre os membros de uma equipa e a continui-

*Médica de Família na USF Conde de Oeiras

Professora auxiliar convidada, Departamento de Medicina Geral

e Familiar da FCM-UNL dade de cuidados.

O impacto destas novas formas de relacionamento na comunicação e em particular na informação proporcionada aos utentes poderá ser enorme. Estar frente a um ecrã que não toma o pulso, que não estabelece contacto visual, que não utiliza o gesto e a postura para envolver ou distanciar, que não usa o tom de voz, as pausas e a entoação para serenar e reflectir, desaproveita muitas das nossas habilidades e capacidades mas abre-nos a outros campos de diálogo reflexivo e a outras narrativas. $\mathrm{O}$ «ecrã» possibilita-nos «parar o tempo» $\mathrm{e}$ dá-nos a ilusão de que o podemos alargar. A sua disponibilidade e a sua abertura 24 horas por dia permitem-nos aumentar a acessibilidade. Podemos responder a qualquer hora do dia, fazer rascunhos a que voltamos um pouco mais tarde, ser interrompidos, enviar diverso tipo de anexos. $O$ correio electrónico permite chegar ao local onde está o utente, casa ou trabalho, configurando uma outra forma de fazer domicílios. Tudo fica registado e guardado com a hora e o dia marcados. O tempo dispendido é facilmente cronometrado e o registo da informação é automático. O que se escreve é mais pensado e mais planeado.

A Internet mudou muita coisa no mundo, os cuidados de saúde não são excepção. ${ }^{1}$ Uma das principais fontes de informação em saúde é a Internet. ${ }^{2}$ Podem ser muitas as vantagens e as desvantagens postuladas mas o certo é que essas hipóteses se mantêm não provadas. Há muitas perguntas que se podem colocar sobre o uso do correio electrónico na nossa pratica clínica. Os dois trabalhos publicados neste número da RPCG, de Pinhão ${ }^{3}$ e Granja, ${ }^{4}$ que nos chegaram com pouco tempo de diferença, mostram que existe interesse na sua aplicação e avaliação. O corpo editorial da revista decidiu publicá-los em paralelo pois apresentam objectivos dis- 
tintos e complementam-se. Em ambos se estuda a correspondência estabelecida por correio electrónico entre uma médica de família e os seus utentes num determinado período de tempo. A população onde se originam os casos tem proveniência geográfica distinta, Matosinhos e Cascais. Apesar de ambos serem descritivos e transversais não analisam o correio electrónico da mesma forma nem utilizam a mesma unidade de tempo para esta observação. O estudo de Pinhão ${ }^{3}$ descreve o movimento de mensagens durante 6 meses e o de Granja $^{4}$ analisa este movimento durante 14 meses. Mas a sua grande diferença reside nos óculos que colocam para olhar esta actividade e no filtro utilizado para obter a imagem deste movimento. Pinhão ${ }^{3}$ explicita o modo como deu origem a esta actividade e as normas em que se apoiou para o seu desenvolvimento e classifica as mensagens trocadas mediante os motivos que condicionaram as mesmas. Granja ${ }^{4}$ faz a caracterização dos utentes que utilizam esta via de comunicação estudando o número de assuntos em cada mensagem e descrevendo o seu conteúdo assim como a resposta pelo médico, o número de mensagens geradas, o tempo de resposta e de ocupação. É interessante verificar, apesar das diferenças encontradas nas médias de idades dos utilizadores, mais jovens dez anos em média no norte comparativamente com os do sul, que ambos se aproximam na prevalência encontrada para esta via de comunicação e no volume de mensagens geradas.

A descrição da interacção entre médico e doente/utente via correio electrónico pode ser difícil de descrever mas, à semelhança de outros tipos de interacções, a ordem porque se estabelecem determinado tipo de comportamentos, neste caso de acções, tempo e tom da resposta, é tão importante quanto a própria mensagem, a sua pontuação, clareza, objectividade, precisão e simpatia. O estudo de Granja também descreve o tamanho das mensagens de resposta dadas pelo médico.

As potencialidades das consultas por $e$-mail já foram demonstradas para a prestação de cuidados preventivos, na educação para a saúde e na gestão de algumas doenças crónicas. ${ }^{5}$ Os lembretes são uma forma efectiva de maximizar os benefícios dos cuidados preventivos. O correio electrónico pode ser aqui mais efectivo do que o telefone. Ensaios controlados, randomizados e com amostras aleatórias de programas com intervenções para perder peso, usando este meio de co- municação, obtiveram resultados positivos significativos. ${ }^{6,7} \mathrm{O}$ mesmo se verificou no tratamento da depressão. ${ }^{8}$ Mas este meio de comunicação não traz apenas vantagens. Também apresenta algumas desvantagens. Não estaremos com a sua utilização a aumentar o fosso das desigualdades sociais? A prestar mais cuidados de saúde a quem menos deles precisa ou seja a jovens adultos da classe média? O seu uso não representa uma ameaça para a privacidade $?^{9} \mathrm{~A}$ carga de trabalho tantas vezes apontada como um impedimento a esta pratica não parece ser uma desvantagem, como indica Granja. ${ }^{4}$

Apesar da controvérsia que o seu uso pode condicionar, estamos certos de que os médicos de família portugueses, sobretudo os mais jovens, irão incorporar na prática clínica diária, à semelhança do que já acontece em muitos outros países, as consultas por $e$-mail. Apesar de estarmos na infância quanto à sua utilização, é importante colocar este tema na agenda de investigação, o que significa começar a compreender de forma detalhada as preferências e o modo como se efectiva este tipo de comunicação. Estes dois trabalhos agora publicados vão nesse sentido. ${ }^{3,4}$ Esperamos que outros lhes sigam o passo e se dediquem a estudar quais são as populações que mais beneficiam deste tipo de comunicação ou como é que a introdução desta nova forma de consulta influencia a relação médico-doente.

\section{REFERÊNCIAS}

1. Kamerow D. You've got mail. BMJ 2004 Oct 16; 329 (7471): e324. doi: 10.1136/bmj.329.7471.E324

2. Car J, Sheikh A. Email consultations in health care: 1- scope and effectiveness. BMJ 2004 Aug 21; 329 (7463): 435-8.

3. Pinhão R, Calisto M, Pimentel MA, Fernandes R. Implementação da comunicação médico-doente via endereço electrónico na consulta do médico de família. Rev Port Clin Geral 2009 Nov-Dez; 25 (6): 634-8.

4. Granja M. O uso de e-mail na comunicação com o médico de família:catorze meses de experiência. Rev Port Clin Geral 2009 Nov-Dez; 25 (6): 639-46.

5. Saibil F, Lai E, Hayward A, Yip J, Gilbert C. Self-management for people with inflammatory bowel disease. Can J Gastroenterol 2008 Mar; 22 (3): 281-7.

6. Baulch J, Chester A, Brennan L. Treatment alternatives for overweight and obesity: The role of online interventions. Behav Change 2008; 25 (1): 1-14.

7. Tate DF, Wing RR, Winett RA. Using technology to deliver a behavioural weight loss program. JAMA 2001 Mar 7; 285 (9): 1172-7.

8. Christensen $\mathrm{H}$, Griffiths KM, Jorm AF. Delivering interventions for depression by using randomised controlled trial. BMJ 2004 Jan 31; 328 (7434): 265.

9. Car J, Sheikh A. Email consultations in health care: 2 - acceptability and safe application. BMJ 2004 Aug 21; 